\title{
La política criminal vista desde la justicia restaurativa en México*
}

\author{
Criminal policy seen from the perspective of the restorative justice in Mexico
}

Julio Cabrera Dircio**

Fecha de recepción: 22 de agosto del 2019

Fecha de aprobación: 5 de diciembre del 2019

\section{RESUMEN}

Desde el punto metodológico, en este artículo partimos del método científico con el que se busca ampliar el conocimiento de estos conceptos: el método dialectico que pretende abrir un diálogo acerca de estos temas, que son de suma importancia, y varios más como el comparativo, el deductivo y el inductivo, pues uno de los principales problemas que existen en México es el alto grado de violencia que se padece en todas las esferas de la sociedad. De esta manera, la justicia restaurativa tiene como objetivo trabajar de forma colaborativa con la política criminal cumpliendo como un factor fundamental en busca de una convivencia armónica. Se formula como hipótesis final que quienes interactuamos con base en el respeto mutuo, de modo que la dignidad humana se vea reflejada en el reconocimiento recíproco y en el respeto de la persona, generemos políticas públicas que busquen resolver a fondo este tipo de problemas, todo ello con base en un proceso cuyo eje rector sea el ser humano, y que se

\footnotetext{
Este artículo es resultado del proyecto de investigación denominado "La justicia restaurativa en la política criminal", gestionado entre la Universidad Autónoma del Estado de Morelos (México) y el Grupo de Investigación Red de Política Criminal Sistémica "Extrema Ratio" UN, reconocido y clasificado A1 por Minciencias 2018, de la Universidad Nacional de Colombia.

Citar como Cabrera Dircio, J. (2020). La política criminal vista desde la justicia restaurativa en México. Via Inveniendi et Iudicandi, 15(1), 161-187. DoI: https://doi.org/10.15332/19090528/5745

* $\quad$ Máster en gobernanza global y derechos humanos por la Universidad de Castilla La Mancha (España), 2018. Doctor en Derecho de la Benemérita Universidad Autónoma de Puebla (México). Profesor investigador de tiempo completo, titular C, definitivo, responsable del cuerpo académico Estudios Jurídicos Constitucionales. Integrante del Comité Científico en representación de México ante el Instituto de Resolución de Conflictos de la Universidad de Castilla La Mancha (España). Exjefe de la unidad de estudios superiores de posgrado de la facultad de derecho de la Universidad Autónoma del Estado de Morelos. E-mail: dr.juliocabreradircio@ hotmail.com. ORCID: https://orcid.org/0000-0002-1081-0424
} 
VIeI Revista Virtual

Via Inveniendi et Iudicandi

identifique con el rol que desempeńa en el grupo social, con el fin de construir una sociedad responsable.

Palabras clave: justicia restaurativa, política criminal, dignidad humana.

\section{Abstract}

In this article we start from the methodological point of view in terms of the scientific method in order to expand the knowledge of these concepts: the dialectical method, which aims to favor a dialogue about those issues that are of utmost importance, and several others such as the comparative, deductive, and inductive ones, provided that one of the main problems in Mexico is the high level of violence that all spheres of society are suffering. In this way, restorative justice aims to work in cooperation with criminal policy playing a fundamental role in search of a harmonious coexistence. A final hypothesis states that those of us who interact on a mutual respect basis, with human dignity reflected in reciprocal recognition and respect for the person, promote public policies that seek to deeply solve these types of problems. All these purposes are developed according to a process which guiding axis is the human being, identifying ourselves with the role played in our social group and trying to build a responsible society.

Keywords: restorative justice, criminal policy, human dignity. 


\section{INTRODUCCIÓN}

La pretensión punitiva del Estado acoge el derecho penal como un instrumento para llevar a cabo el ejercicio de dicha potestad monopólica; es decir, la potestad de la investigación y persecución de los delitos y de los sujetos probables a quienes habrá de aplicarse una sanción, además de que resarzan el daño a la víctima y restauren el orden social.

Debe entenderse la política como ciencia y arte de gobernar que trata de la organización y administración de un Estado y que está constituida por comunidades que pretenden como fin algún bien, pero, sobre todo, el bien superior al que llamamos ciudad y comunidad cívica. Se parte así de que todos los hombres y mujeres somos iguales para poder subsistir los unos con los otros por la naturaleza como la familia para buscar la autosuficiencia total (Aristóteles, 2017).

La política criminal (Huertas, 2019) es considerada como el estudio del conjunto de medidas empleadas por los órganos de gobierno para enfrentar la criminalidad que afecta a un Estado, con la intención de encontrar soluciones pertinentes para disminuir los niveles de delincuencia. Uno de los principales problemas que se identifican es que los centros de reinserción se encuentran sobrepoblados y existe un hacinamiento de personas que hacen casi imposible que, al ser liberados y empezar a realizar sus actividades de manera normal, realmente puedan hacerlo, pues tienen que afrontar la estigmatización de la misma sociedad antes de que puedan encontrar un empleo con el que puedan subsistir tanto ellos como sus familias o las personas que dependan de ellos (Molina, 2016).

En particular, en México la utilización de las medidas alternativas a la prisión preventiva constituyó una de las principales recomendaciones de la Comisión Interamericana de Derechos Humanos (CIDH), en su informe sobre prisión preventiva del 2013, a fin de racionalizar el uso de la prisión preventiva y, por consiguiente, enfrentar el hacinamiento (CIDH, 2013).

La modernidad que es característica de nuestro siglo ha ido de la mano con la pérdida de ciertos valores en el comportamiento humano; esto ha desatado una serie de elementos violentos en nuestro comportamiento que han dado como resultado, 
en conflictos violentos en los órdenes político, económico y social, en los que la desconfianza ha logrado permear en gran parte los estratos sociales.

La tutela judicial efectiva a la que debemos tener acceso todos los que habitamos en el orbe, establecida en la Declaración Universal de los Derechos Humanos (sobre la tutela judicial, artículo 8), establece que toda persona tiene derecho a un recurso efectivo, ante los tribunales nacionales competentes, que la ampare contra actos que violen sus derechos fundamentales reconocidos por la Constitución, pero se ve totalmente vulnerada todos los días debido a la violación constante que se le impone.

Los índices que manejan los organismos internacionales son en verdad graves; así se observa en la información más reciente a toda escala: mundial, nacional y local, lo que de verdad es alarmante. Por ejemplo, en junio del 2018 se divulgó la evaluación de los países menos violentos (GPI), único estudio que cuantifica la paz mundial, elaborado por el Institute for Economics and Peace (IEP). En este año se lo amplió para clasificar a 163 estados independientes. Está compuesto por 23 indicadores cualitativos y cuantitativos, de fuentes muy respetadas, y mide el estado de paz utilizando tres dominios temáticos: el nivel de seguridad social, el alcance del conflicto nacional e internacional en curso y el grado de militarización (Institute for Economics and Peace (2018).

Esto indica que vivimos en una sociedad en la que los conflictos cada día son mayores y que es necesario explorar nuevos paradigmas respecto de la respuesta del Estado, la víctima u ofendido, el inculpado y la comunidad, de frente al conflicto en el área penal, pues solo de esta manera podremos encontrar alternativas de solución con la participación de todos los sectores de la sociedad encaminados al bien común.

Para Rousseau, "siendo todos los ciudadanos iguales por el contrato social, todos pueden mandar lo que todos deben hacer, pero nadie tiene derecho de exigir que otro haga lo que él no hace" (Rousseau, 2000); por lo tanto, la reciprocidad en este nuevo paradigma cumple un factor fundamental en busca de la paz que siempre es necesaria para vivir en armonía, de modo que quienes integramos ese grupo social en el que interactuamos también seamos participes en la solución. 


\section{LIBERALISMO DEMOCRÁTICO}

En el liberalismo democrático, todos debemos ser partícipes en la solución de los conflictos que nos aquejan día con día, con el fin de crear un espacio donde la convivencia social sea el eje alrededor del cual todos encontremos una motivación para trabajar de manera colaborativa. Se procura generar en sí mismo y en las nuevas generaciones el deseo de vivir en armonía con nuestros semejantes, pues para ejercer nuestras libertades necesitamos que estas sean respetadas por aquellos con quienes interactuamos (Guarín y Aldana, 2016).

Una de las características del liberalismo democrático son las libertades que poseen las personas al tomar decisiones, como en el caso de los presupuestos participativos donde los ciudadanos por sí mismos participan en la asignación de los recursos para las obras solicitadas y al mismo tiempo y al mismo tiempo fiscalizan las obras solicitadas y están al pendiente que sean aplicadas en lo previsto.

En una sociedad tan compleja como en la que estamos viviendo y cuya gobernabilidad democrática se ve rebasada por los conflictos y por la incapacidad de la autoridad para enfrentarlos de manera adecuada, además del cambio de paradigma en materia de justicia restaurativa, el inculpado debe asumir frente a la víctima u ofendido su responsabilidad por el daño causado, lo que debe orientarse a buscar conciencia en la persona y de esta para con la sociedad.

\section{EL CONFLICTO}

El conflicto en el proceso penal hacen que las partes se vuelvan protagonistas y ellos mismos participen y sean protagonistas de sus propios problemas buscando alternativas de solución actuando siempre de manera racional y que la solución sea el resultado de un acuerdo entre las partes, evitando que la victima sea perdedora por partida doble, primero frente al delincuente y despues frente al estado al negarsele el derecho a la plena participación en el proceso (nils,1992).

En el proceso cultural que se ha desarrollado en materia penal, en el que cada persona se desenvuelve con una ideología particular, se puede observar cómo "el sistema 
es como una cadena sobre la cual avanza el imputado: cada uno de los encargados aprieta, por ende, su respectivo perno, y al final de la cadena sale terminado el producto del sistema" (Hulsman, 1984); por lo tanto, es muy frecuente que una autoridad considere que la otra fue la que ejecutó mal su trabajo. Todo ello permite afirmar que se trata de un conjunto de instituciones con constantes problemas de coordinación, difíciles de controlar.

En la justicia retributiva, la víctima es perdedora por partida doble: primero, frente al Estado y después, frente al delincuente. De esta manera, el concepto de justicia al que aspiramos en una sociedad organizada se pierde y el Estado, en representación de la víctima y de la sociedad, no cumple en lo más mínimo con esta función a la que está destinado, de modo que la funcionalidad del derecho como medio de control social no se logra.

En México, gran parte de la problemática en la que nos encontramos inmersos es el resultado de políticas públicas que no han respondido a la realidad social en la que vivimos. Esto se ve reflejado, en primer lugar, en el comportamiento de las personas: algunas tolerantes y reflexivas, otras agresivas y violentas, lo que da nacimiento a una fase conflictiva como sociedad disfuncional en la que cada uno responde a sus intereses particulares y no del grupo.

El rompimiento de paradigma que estamos viviendo en nuestro país a partir de la reforma constitucional del 2008 en materia penal y de la del 2011 en relación con los derechos humanos demuestra que frente a la problemática que tenemos en México y en el mundo, la única forma de buscar una alternativa de solución es haciendo que la sociedad se responsabilice de sus propios problemas y que participemos de manera directa en la problemática social en la que estamos inmersos.

\section{LA JUSTICIA RESTAURATIVA}

Por tratarse de algo novedoso, la implementación en nuestro país de la justicia restaurativa no es una opción fácil, pues implica una nueva forma de pensar y de actuar. Es difícil que el infractor tenga un sentido de culpabilidad y que quiera aceptar las consecuencias del ilícito de manera directa, sobre todo, teniendo que enfrentar a la 
víctima u ofendido y que él también quiera tener contacto con el inculpado, pues le resulta muy difícil después de haber pasado por esa amarga experiencia. La sociedad debe estar preparada para saber cómo actuar ante situaciones de este tipo, buscando no solo la solución del conflicto, sino también la recomposición del tejido social.

Este modelo integrador hace que la participación de la víctima y la sociedad sean los protagonistas del procedimiento en el conflicto penal, pues la participación del Estado se da de manera mínima; por lo tanto, su desarrollo debe ser exclusivo de quienes fueron los generadores del conflicto y han de buscar alternativas de solución que impacten también en el grupo social en el que interactúan.

La acción monopólica del Estado en materia penal pasa a segundo término, pues la pena y su vigilancia son dos elementos que no han podido resolver la problemática de la sociedad. Como dice Hernández Gil (1981), no es fácil describir el proceso discursivo en la construcción jurídica, pues entre él y la práctica hay una falta total de correspondencia, ya que los ordenamientos jurídicos implican demasiada carga especulativa en la formación de criterios y reglas de comportamiento, mientras que en el iusnaturalismo, la lógica aparece asociada con la ética y la dogmática se asocia con la historia, no en cuanto a la expresión de la realidad social.

La justicia restaurativa es un modelo que busca generar conciencia en la ciudadanía sobre la pacificación con base en las relaciones humanas buscando soluciones conciliadoras del conflicto penal y flexibilizando y simplificando el procedimiento. En ella, las figuras jurídicas como la mediación y la conciliación han de coadyuvar y responder a la necesidad misma de la sociedad y sus partes implicadas, sobre todo las de la víctima u ofendido, ya que cuando el delito corresponde a un conflicto intersubjetivo, puede ser canalizado a un facilitador que apoye a su resolución.

No, olvidemos que, en cualquier procedimiento, la figura del juez siempre es el actor principal y, por lo tanto, es falible al momento de emitir una resolución. Según Jerome Frank (1991), el juez, al resolver, se basa en creencias sobre los hechos pasados observados por él. Los testigos mienten las mayoría de las veces y los honestos yerran con frecuencia como ocurre con las partes cuando llegan ante el juez y siguen pensando que tienen la razón. Estos hechos hacen que los jueces y los jurados sean falibles al tomar una determinación que dejen satisfechos a quienes participaron. 
En vedad, el Estado ha sufrido transformaciones a través de la historia y esta evolución se refleja principalmente en el poder: es el elemento que más transformaciones ha presentado, lo que se debe principalmente a que son las propias reglas impuestas por la sociedad las que han pretendido limitar y encauzar su acción, buscando que realmente nos pueda ser de utilidad, para que así se pueda encontrar una respuesta adecuada a la problemática social.

En este sentido, según Aristóteles (2017), “a cada individuo le sobreviene tanta felicidad como sea su virtud, su inteligencia y su forma de obrar"; así mismo, "el valor de una ciudad, su justicia y su temple equivalen y son semejantes a las virtudes por cuya posición se llama a los individuos valientes, justos, sabios y prudentes”. En las polis griegas, en su organización interna, siempre se buscó llegar a ese mundo ideal en el que la felicidad fuera el común denominador de una sociedad que aspira a una mejor calidad de vida y en la que sus actividades estuvieran encaminadas a ese fin: que fueran deseables y sensatas.

En Latinoamerica, pero sobre todo en México, hay cierta resistencia a estos cambios. Todavía se sigue pensando que el Estado es el que debe encargare de resolver todos los problemas propiciados por la ciudadanía. Hace falta que un proceso cultural permee en la sociedad, de modo que podamos, de manera directa, ejercer todos nuestros derechos, pero también cumplir con nuestras obligaciones y encaminarnos a uno de los fines del Estado, como es el bien común.

En México la problemática que enfrentamos en la realidad del discurso nos lleva a establecer que contamos con una legislación acorde que responde a las necesidades de la sociedad siempre cambiante, pero porque ella no se ve reflejada en el comportamiento de la sociedad. Las cifras que manejan organismos internacionales y nacionales son alarmantes debido al índice de crecimiento de las violaciones constantes en esta materia

\section{Problemática en el Ámbito internacional}

A pesar de los esfuerzos de organismos internacionales, como la Organización de las Naciones Unidas, para lograr que los países miembros se concienticen de que este es un 
problema que afecta a la humanidad y de que es importante trabajar en este sentido, en la Comisión de Prevención del Delito y Justicia Penal celebrada en Viena del 16 a 25 de abril del 2002, en el debate temático sobre la reforma del sistema de justicia penal: logro de la eficacia y la equidad, se trató de encontrar un concepto sobre lo que se pudiera entender como justicia restaurativa. Se lo denominó entonces en estos términos:

Por "proceso restaurativo" se entiende todo proceso en que la víctima, el delincuente $y$, cuando proceda, cualesquiera otras personas o miembros de la comunidad afectados por un delito, participen conjuntamente de forma activa en la resolución de cuestiones derivadas del delito, por lo general con la ayuda de un facilitador. Entre los procesos restaurativos se puede incluir la mediación, la conciliación, la celebración de conversaciones y las reuniones para decidir sentencias.

En el ámbito internacional, encontramos que gran parte de los países América Latina están entre los más violentos. Esto se refleja en el comportamiento de quienes vivimos en estos países. Así, es muy frecuente que cuando visitamos otro país, quien nos invita nos enuncia y la primera recomendación: que nos cuidemos y no vayamos a caminar por lugares donde no se encuentre vigilancia o bien, que no lo hagamos de noche y que, de preferencia, lo hagamos acompañados.

En junio del 2018 se publicó el estudio con la evaluación de los países menos violentos. Esta es la clasificación dentro de la región a partir del menos violento, según el lugar que ocupa cada uno: Canadá: 8, Chile: 28, Uruguay: 37, Costa Rica: 40, Panamá: 50, Argentina: 66, Nicaragua: 68, Perú: 74, Ecuador: 75, Paraguay: 77, Cuba: 81, Guayana: 82, Trinidad y Tobago: 84, Haití: 88, Jamaica: 90, Republica Dominicana: 91, Bolivia: 94, Brasil: 106, Guatemala: 111, El Salvador: 116, Honduras: 118, Estados Unidos: 123, México: 140, Venezuela: 143, Colombia: 145 (Global Peace Index, 2019).

El Instituto para la Economía y la Paz en México (IEP) analiza ocho pilares de paz positiva; es decir, los factores que sostienen a las sociedades pacíficas: buen funcionamiento del gobierno, distribución equitativa de los recursos, libre flujo de información, entorno empresarial sólido, alto nivel de capital humano, aceptación de los derechos de los demás, bajos niveles de corrupción y buenas relaciones con los vecinos. 
En México, tres de estos pilares muestran gran fragilidad: buen funcionamiento del gobierno, libre flujo de información y bajos niveles de corrupción. Como reflejo de lo anterior, el porcentaje de mexicanos que dijeron tener altos niveles de confianza en instituciones de seguridad pública fue de $18 \%$ en el 2017, el nivel más bajo desde el 2012. Así mismo, el $64 \%$ de los mexicanos percibieron las instituciones de seguridad pública como corruptas y el $70 \%$ tuvieron una percepción similar sobre los jueces (Instituto para la Economía y la Paz en México, IEP, 2018).

Carlos Juárez, director del IEP, escribió: "Hemos encontrado que la preocupación de la sociedad mexicana sobre la impunidad y su confianza en los jueces se relaciona directamente con las alzas y bajas de la violencia” (IEP, 2018). Recuperar y fortalecer la confianza pública será de suma importancia para implementar políticas públicas que sean creíbles para su aplicación práctica buscando recomponer el tejido social; aquí es exactamente donde se tiene que trabajar con la justicia restaurativa.

La confianza en el ámbito político descansa en la reciprocidad, cuya condición depende de la percepción del compromiso de las personas que están dispuestos a contribuir para su desarrollo, confiando en que cada uno participe en las acciones que le corresponden como incentivo para que todos realicen de la misma manera las actividades con base en el respeto y la solidaridad. Ello implica que los beneficios y cargas se distribuyan de manera equitativa (Turégano, 2013).

La reciprocidad puede verse como la motivación para que un acto realizado por una persona sea repetido con el afán de que todos participemos en acciones que son necesarias y, por tanto, reconocidas por cada integrante del grupo social, y que estemos dispuestos a contribuir compartiendo la misma necesidad y disposición para su realización; todos nos sentimos comprometidos a corresponder las acciones de todos los ciudadanos.

\section{Problemática en México}

En México, el Instituto Nacional de Estadística y Geografía (INEGI), en un estudio desarrollado en la Encuesta Nacional sobre Victimización y Percepción sobre Seguridad Pública (envipe) (véase el gráfico 1) establece datos que llevan a una reflexión sobre por qué la causa de la funcionalidad del derecho no se ve reflejada en el 
comportamiento de los habitantes de nuestra nación (INEGI, 2018). En este sentido, la ENVIPE permite estimar que la cifra negra fue en todo el país, en el 2017, de 93,2\%, cifra estadísticamente equivalente a la estimación de 93,6\% del 2016 (INEGI, 2018).

Gráfico 1. Datos de la cifra negra en México (2012-2017)

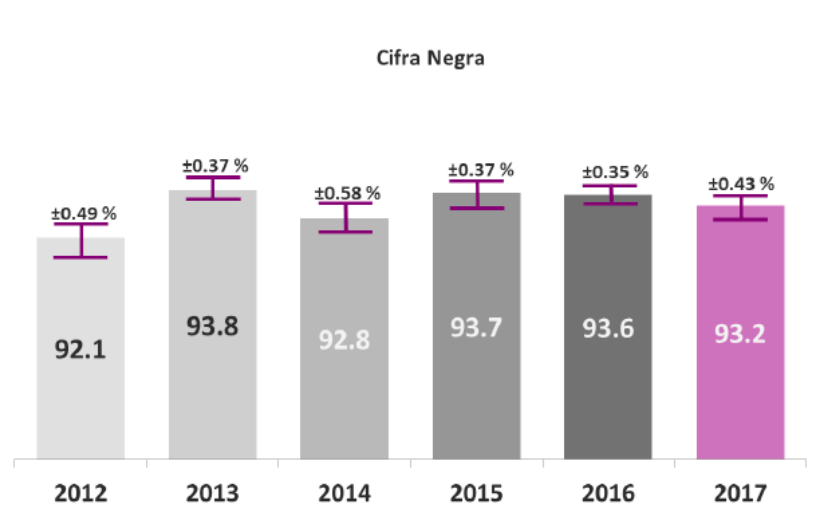

\begin{tabular}{|l|c|}
\hline \multicolumn{2}{|c|}{ Cifra Negra 2017} \\
\hline Tipo de delito & Porcentaje \\
\hline Otros delitos & \\
\hline Extorsión & 98.3 \\
\hline Fraude & 98.2 \\
\hline Robo parcial de vehículo & 95.5 \\
\hline Otros robos & 95.0 \\
\hline Secuestro & 94.4 \\
\hline $\begin{array}{l}\text { Robo o asalto en la calle o } \\
\text { en el transporte público }\end{array}$ & 94.1 \\
\hline Amenazas verbales & 94.1 \\
\hline Robo en casa habitación & 89.0 \\
\hline Lesiones & 85.7 \\
\hline Robo total de vehículo & 32.5 \\
\hline
\end{tabular}

Fuente: Instituto Nacional de Estadística y Geografía (INEGI, México). Encuesta Nacional sobre Victimización y Percepción sobre Seguridad Pública. 25 de septiembre del 2018.

El derecho, como un medio de control social, debe favorecer certeza y certidumbre para quienes deban acudir ante la autoridad a denunciar cualquier situación en la que se vea afectado su patrimonio o su integridad física. Si las personas no acuden, es porque existe cierta desconfianza que ha sido generada por el mal desempeńo de los operadores jurídicos o, bien, porque el ordenamiento jurídico que se aplica no responde a sus necesidades.

Para Rawls (2003), en la justicia como imparcialidad, la sociedad se interpreta como una empresa cooperativa para beneficio mutuo, y esto establece un esquema de actividades que conducen a las personas a actuar de manera conjunta, de modo que obtengan un mayor beneficio otorgando ciertos derechos reconocidos y que compartan sus beneficios. Lo que haga una persona depende de las reglas públicas para satisfacer sus pretensiones, lo que le permite visualizar cuáles son sus expectativas y hacia dónde debe enfocarlas. 
Entre las razones para no denunciar delitos ante las autoridades en México (véase el gráfico 2$)$, se destacan la pérdida de tiempo $(34,2 \%)$ y la desconfianza en la autoridad (16,5\%), dentro de las causas atribuibles a la autoridad (INEGI, 2018).

Gráfico 2. Razones para no denunciar delitos ante las autoridades (México, 2018)
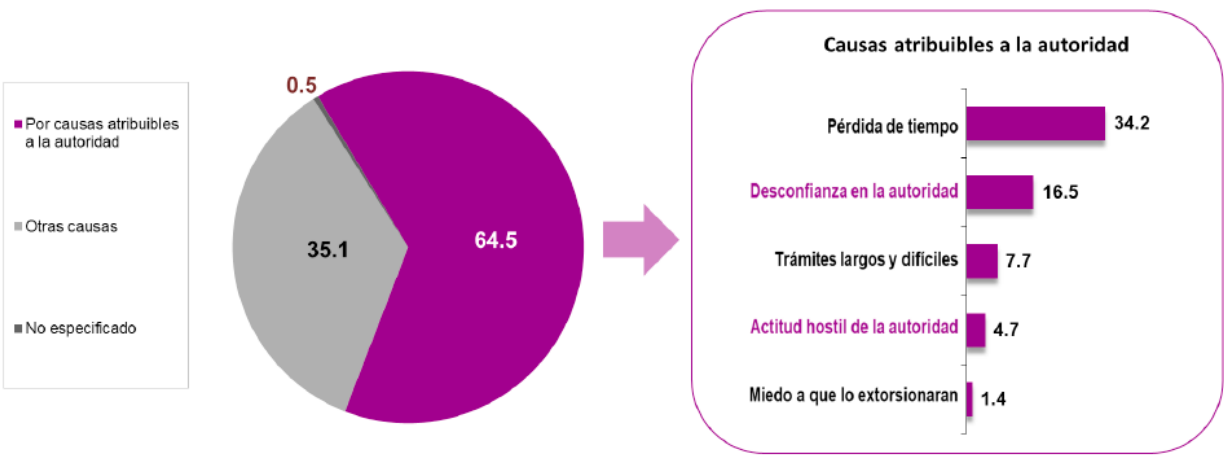

Por otras causas se entienden: miedo al agresor, delito de poca importancia, no tenía pruebas y otros motivos.

Fuente: Instituto Nacional de Estadística y Geografía (INEGI, México). Encuesta Nacional sobre Victimización y Percepción sobre Seguridad Pública. 25 de septiembre del 2018.

¿Cuál es la problemática por la que en México las personas no se presenten a denunciar ante la autoridad cuando se vean afectados en su integridad física o en su patrimonio? Las cinco supuestas causas que se exponen ofrecen una visión realista de la problemática por la que atravesamos, referida esta al sistema jurídico o, en su caso, a la persona, lo que se relaciona con una percepción generalizada de que no vale la pena acudir ante las autoridades para denunciar si no se va a llevar a cabo un procedimiento confiable.

Según Weber (2002), el derecho es un sistema que cuenta con dos subsistemas: uno de ordenación e integración del ordenamiento jurídico y otro de resolución de conflictos, pero cuando falla uno, el otro no puede suplirlo porque se trata de un conjunto de relaciones entrelazadas con un solo fin: brindar seguridad y certeza jurídica y que, de forma dinámica, se tenga que ir adecuando según las circunstancias que vayan prevaleciendo en los grupos sociales en los que se pretende aplicar. Esto favorece la convicción de que el sistema jurídico y la autoridad responden a las necesidades sociales y de que orienta un derecho racional y formal. 
El problema de un sistema jurídico que no logra constituirse en un medio de control social se ve reflejado en una incompatibilidad que produce su invalidez desde antes de poner en marcha los órganos encargados de hacerlo valer. Esto es el reflejo de lo que estamos viviendo en una sociedad como la nuestra, en la que cada día los conflictos son más complejos y la toma de decisiones se vuelven más difíciles, lo que implica que, desde el ámbito subjetivo, la persona asuma una actitud generalizada de pérdida de confianza al constatar que no se satisfacen sus necesidades.

Su impacto se aprecia de manera directa en la justicia restaurativa, en la cual, al no existir reciprocidad entre el componente social, se identifica una falta de reconocimiento y de respeto que impide desarrollar de manera armónica las actividades propias de la sociedad. Así, el beneficiario de los derechos estima que no existe la capacidad del Estado para hacerlos valer y, por lo tanto, los individuos deben contribuir desde su interés personal a los intereses colectivos.

Esto se ve reflejado en algunos documentos que se encargan de medir el funcionamiento de la sociedad. La Comisión Interamericana de Derechos Humanos ha desarrollado varios estudios sobre el estado actual de los derechos humanos, lo que puede observarse en el gráfico 3 (CIDH, 2017).

Gráfico 3. Peticiones recibidas por año en México (1997-2017)

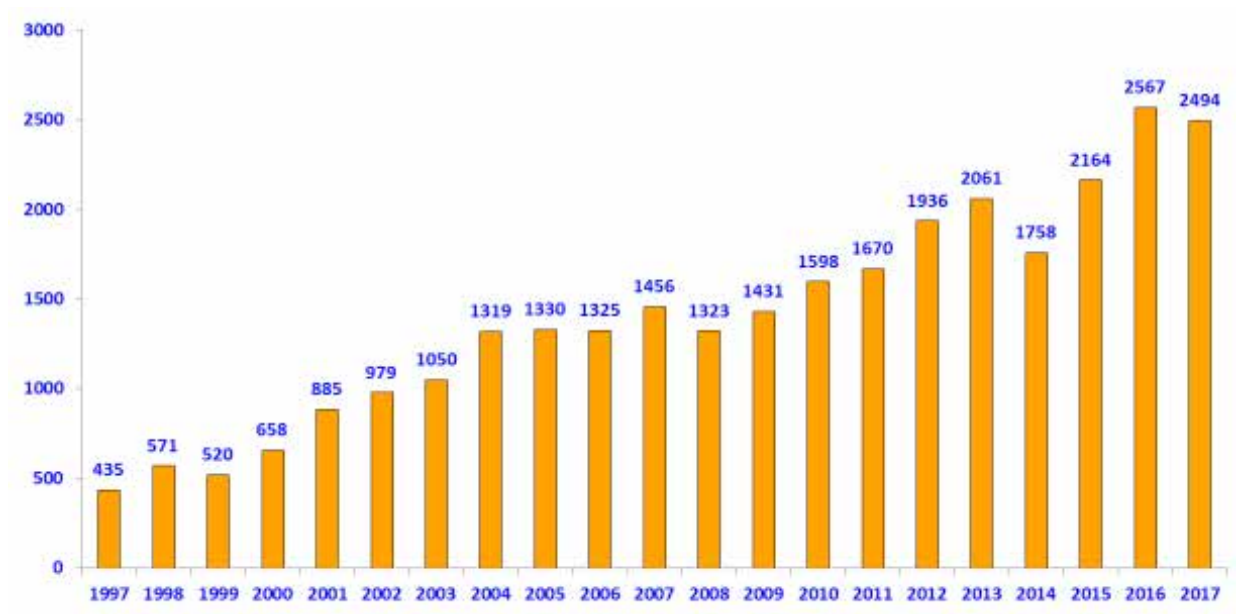

Fuente: Comisión Interamericana de Derechos Humanos (2017). Capítulo II. Peticiones, casos y medidas cautelares. En Informe anual 2017. (p. 56). 
De manera generalizada, este grafico muestra cómo la conflictividad social se ve reflejada en el crecimiento de la espiral señalada, salvo algunos casos de los ańos 2008, 2014 y 2017. Ello demuestra el crecimiento que se da de peticiones a los organismos internacionales cuando se infringe el respeto por los derechos humanos.

Un problema grave que podemos señalar es que, de 2494 peticiones en el 2017 (gráfico 4), la CIDH aprobó 120 informes de admisibilidad, lo que constituyó un récord histórico. Se trata de 35 informes de fondo (más del doble de los aprobados el año anterior) del mayor número de reuniones de trabajo de su historia para facilitar acuerdos de soluciones amistosas; así mismo, otorgó 45 medidas cautelares. También se logró reducir a un mínimo histórico el número de peticiones en etapa de estudio inicial y evaluó el $100 \%$ de las peticiones recibidas en el ańo previo. Ha mantenido asimismo un diálogo y armonización periódica con la Corte Interamericana, ha enviado 18 casos a la Corte, cuatro solicitudes de medidas provisionales y ha retomado el envío de solicitudes de opiniones consultivas tras casi 10 años sin hacerlo. De esta manera, la CIDH alcanzó sus primeros objetivos para fortalecer el sistema de casos y peticiones y reducir el atraso procesal y para activar resultados concretos con miras a hacer más eficiente y oportuna la respuesta para los usuarios del sistema (CIDH, 2017). 
Gráfico 4. Peticiones recibidas por país en el 2017

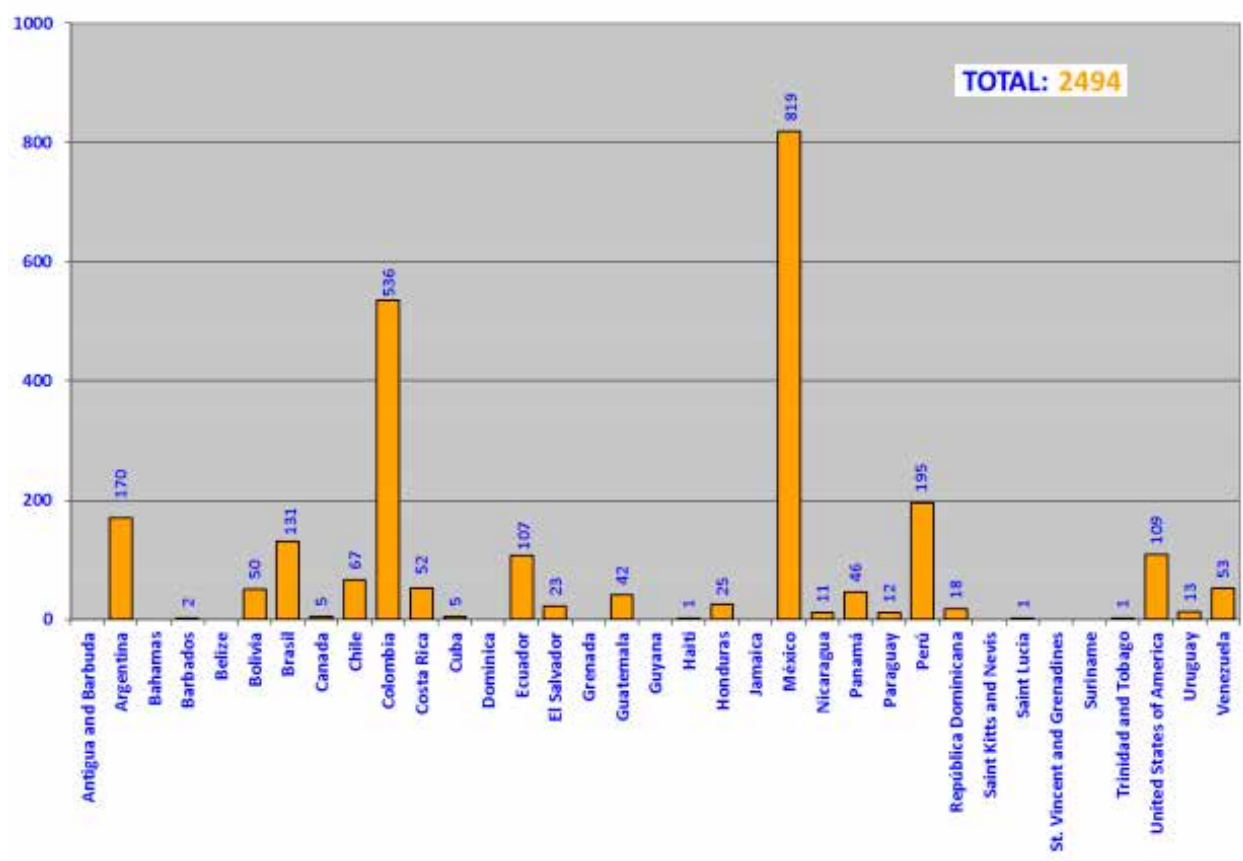

Fuente: Comisión Interamericana de Derechos Humanos (2017). Capítulo II. Peticiones, casos y medidas cautelares. En Informe anual 2017. (p. 55).

Se aprobaron 120 informes de admisibilidad de 2494 peticiones y quedaron por resolver 2374. Esto demuestra que gran parte de la problemática en esta materia no es tan fácil de resolver, lo que hace que estos organismos internacionales no cumplan con la función para la que fueron establecidos. Es una sociedad que se encuentra desconfiada de estas instituciones en el plano nacional o incluso estatal y municipal.

A partir de estos documentos, puede observarse que gran parte del contenido de los textos normativos anteriores (Declaración Universal de los Derechos Humanos de 1948 y de organismos específicos como el Alto Comisionado) han quedado en el campo del idealismo y que se trata de reglamentaciones de escasa aplicación, y que los países firmantes de los tratados internacionales en América Latina únicamente tratan de cubrir un requisito de su política internacional, sin que ello implique su aplicación. 


\section{Respuesta a la problemática}

En América Latina se ha buscado partir de los altos índices de violencia para formular una respuesta jurídica que ayude a encontrar un elemento preventivo que coadyuve en la generación de la seguridad de que la aplicación de la ley nos lleve a establecer una regla formal de la conducta humana; se cumplirían así ciertas formalidades, sobre todo al establecer límites materiales al momento de su aplicación.

De esta manera, se han dado una serie de reformas que buscan generar un derecho más humano, que sea más accesible para quienes tienen la necesidad de resolver algunas acciones que han generado diferencias en el interactuar de la sociedad, en busca de alternativas de solución al conflicto presentado, con el ánimo de lograr una elección lo más adecuada posible y que responda a sus intereses siempre en pos del mejor arreglo.

\section{Colombia}

En este país suramericano se promulgó una nueva Constitución en 1991, con 380 artículos, que algunos categorizan como la constitución de los derechos humanos, que busca aplicar la justicia alternativa con base en los siguientes ordenamientos jurídicos.

— Constitución Política de Colombia (1991), artículo 116;

— Ley 23 de 1991;

— Ley 270 de 1996, modificada por la Ley 1285 del 2009;

— Ley 446 de 1998;

- Decreto 1818 del 1998;

— Ley 640 de 2001;

— Ley 1563 de 2012;

- Decreto 1829 de 2013;

- Marco constitucional y legal. 
La Corte Constitucional, la Corte Suprema de Justicia, el Consejo de Estado, el Consejo Superior de la Judicatura, la Fiscalía General de la Nación, los tribunales y los jueces administran justicia. También lo hace la justicia penal militar. El Congreso ejerce determinadas funciones judiciales. Excepcionalmente, la ley puede atribuir función jurisdiccional en materias precisas a determinadas autoridades administrativas; sin embargo, no se les permite adelantar la instrucción de sumarios ni juzgar delitos. Los particulares pueden ser investidos transitoriamente con la función de administrar justicia, en condición de jurados en causas criminales, como conciliadores o como árbitros habilitados por las partes para proferir fallos en derecho o en equidad, en los términos que determine la ley.

En este país hay muchos avances desde el punto de vista jurídico, aunque no se tengan los resultados que se esperan. Han aplicado reformas para que las universidades establezcan de manera obligatoria los centros de conciliación y que, además, los alumnos tengan que realizar un periodo de prácticas internas y vincularse de manera real a esta nueva forma de aplicar justicia, en la que el ser humano es el eje rector del procedimiento.

Algo que también llama la atención es la conciliación en equidad, mediante la cual las personas pueden prepararse para ofrecer estos servicios, pues no necesariamente hay que ser profesional. Por lo tanto, cualquier persona puede recibir esa preparación si desea realizar esta actividad en beneficio de la sociedad en donde interactúa y en la cual el fin principal es abordar los conflictos de manera tal que se pueda poder construir una sociedad más responsable.

\section{Argentina}

El primer antecedente sobre el cual se cimentó el desarrollo de los métodos (RAD) Procedimientos de Resolución Alternativa de Disputas, en el país fue el Decreto 1480 del 19 de agosto de 1992, por el cual se declaró de interés nacional la mediación y se implementó el Programa Nacional de Mediación. A partir de dicha normativa, se creó el primer centro de mediación, dependiente del entonces Ministerio de Justicia, y se implementó la Experiencia Piloto de Mediación, por la cual diez juzgados civiles patrimoniales y de familia (luego fueron veinte) comenzaron a derivar causas a este centro. Allí hicieron sus prácticas y la observación de casos reales los primeros mediadores del país. A su vez, se creó la Comisión de Mediación por Resolución 
Ministerial n. ${ }^{\circ}$ 297/91, integrada por prestigiosos miembros, jueces, abogados y académicos, a la que se le encomendó la creación de un Proyecto de Ley Nacional de Mediación.

En consideración a que la justicia ofrecía un cuadro de emergencia que ponía en peligro el sistema, el poder ejecutivo promulgó el 8 de noviembre de 1994 un proyecto de ley de mediación prejudicial obligatoria, en cuyo mensaje al Congreso de la Nación sostuvo:

La situación de notoria crisis en que se encuentra la justicia justifica la introducción de soluciones que procuran responder a esta emergencia. A través de aquellas medidas se intenta reducir el alto nivel de litigiosidad que nuestros tribunales padecen actualmente, al mismo tiempo, se intenta provocar una mayor celeridad en la solución de las cuestiones que deban ser resueltas judicialmente, ya que parte de la gran masa de juicios que abarrotan los juzgados, será desviada por medio de estos métodos alternativos [...]. (PNUD Argentina, 2012)

El gran problema de argentina es el mismo que se vive en toda América Latina, salvo algunas excepciones. Así, puede verse, por ejemplo, lo que establece el índice global por la paz (GPI), en su informe del 2017, que proporciona una actualización completa sobre el estado de paz. Muestra que, en medio del deterioro global, el mundo sigue gastando enormes recursos para crear y contener la violencia, pero muy poco en la paz. La clave para revertir la disminución de la paz es a través de la construcción de paz positiva, un marco holístico de las actitudes clave, las instituciones y las estructuras que construyen la paz en el largo plazo. El objetivo de desarrollo sostenible 16, de las Naciones Unidas, centrado en la paz, la justicia y las instituciones fuertes, es fundamental para enfocar a la comunidad internacional en el objetivo de lograr un mundo más pacífico.

\section{México}

Al igual que en los otros países, se llevaron a cabo varias reformas para resolver la problemática que hay en materia de violencia y las afectaciones que impactan los aspectos, político, económico y social. Así, se destaca la reforma constitucional en 
materia penal del 2008, que establece la oralidad en los juicios del orden penal y la justicia alternativa, y la del 2011, que aplica una reforma en materia de derechos humanos y en la que, de manera directa, se habla de aplicar el principio pro persona.

La Ley Nacional de Mecanismos Alternativos de Solución de Controversias en Materia Penal, publicada en el Diario Oficial de la Federación el 29 de diciembre del 2014, establece algunos elementos que favorecen mayor participación de quienes soliciten algún servicio en materia de procuración de justicia, cuyo objeto general se expone en seguida.

\section{Artículo 1. Objeto general}

Las disposiciones de esta Ley son de orden público e interés social y de observancia general en todo el territorio nacional y tienen por objeto establecer los principios, bases, requisitos y condiciones de los mecanismos alternativos de solución de controversias en materia penal que conduzcan a las Soluciones Alternas previstas en la legislación procedimental penal aplicable.

Los mecanismos alternativos de solución de controversias en materia penal tienen como finalidad propiciar, a través del diálogo, la solución de las controversias que surjan entre miembros de la sociedad con motivo de la denuncia o querella referidos a un hecho delictivo, mediante procedimientos basados en la oralidad, la economía procesal y la confidencialidad. (Ley Nacional de Mecanismos Alternativos, 2014)

Asimismo, ocurre en los principios rectores:

Artículo 4. Principios de los Mecanismos Alternativos Son principios rectores de los Mecanismos Alternativos los siguientes:

I. Voluntariedad: La participación de los Intervinientes deberá ser por propia decisión, libre de toda coacción y no por obligación;

II. Información: Deberá informarse a los Intervinientes, de manera clara y completa, sobre los Mecanismos Alternativos, sus consecuencias y alcances;

III. Confidencialidad: La información tratada no deberá ser divulgada y no podrá ser utilizada en perjuicio de los Intervinientes dentro del proceso penal, 
salvo que se trate de un delito que se esté cometiendo o sea inminente su consumación y por el cual peligre la integridad física o la vida de una persona, en cuyo caso, el Facilitador lo comunicará al Ministerio Público para los efectos conducentes;

IV. Flexibilidad y simplicidad: Los mecanismos alternativos carecerán de toda forma estricta, propiciarán un entorno que sea idóneo para la manifestación de las propuestas de los Intervinientes para resolver por consenso la controversia; para tal efecto, se evitará establecer formalismos innecesarios y se usará un lenguaje sencillo;

V. Imparcialidad: Los Mecanismos Alternativos deberán ser conducidos con objetividad, evitando la emisión de juicios, opiniones, prejuicios, favoritismos, inclinaciones o preferencias que concedan u otorguen ventajas a alguno de los Intervinientes;

VI. Equidad: Los Mecanismos Alternativos propiciarán condiciones de equilibrio entre los Intervinientes;

VII. Honestidad: Los Intervinientes y el Facilitador deberán conducir su participación durante el mecanismo alternativo con apego a la verdad.

Si se alcanza la aplicación del objetivo según el cual quienes participan mediante el diálogo logran resolver sus diferencias con base en los principios rectores, estos serían resueltos de fondo y no habría necesidad, como en la justicia tradicional, de agotar todos los recursos, pues quienes han propiciado el conflicto son los que participan en su solución. De esta manera, empezaríamos a construir una nueva sociedad que sea responsable y en la cual se ejerciten los derechos, pero también se cumplan las obligaciones.

Para que la justicia restaurativa funcione, deben lograrse acuerdos en que las partes sean los actores que, mediante el dialogo, logren resolver sus diferencias, pero también que la sociedad no se vea afectada por este tipo de acciones que favorecen una percepción de que, haciéndolo de manera racional y civilizada, podemos avanzar en conjunto. Esto apoya la armonía que es tan importante en todo grupo social, en el que mediante la reciprocidad se busque la colaboración y cooperación, a fin de hallar un mayor grado de integración. 


\section{Métodos utilizados en el ámbito jurídico}

El método es un resultado de la actividad racional del hombre y constituye un conjunto de reglas sobre la base del conocimiento de la realidad. El método no es otra cosa que lógica aplicada, estrechamente relacionada con la lógica tanto formal como dialéctica. De esta forma, podemos partir tanto del método empírico como del racional, pero también se encuentra vinculada la utilización del método científico, el deductivo, el inductivo y el comparativo.

\section{Conclusiones}

La parte más humana de la justicia se encuentra en la justicia restaurativa. Como hacer valer estos elementos para no caer en el idealismo y forjar una nueva visión de la realidad social que debemos enfrentar para fomentarla, buscando siempre la recomposición social haciéndose responsable cada cual del resultado de sus acciones y de sus posibles soluciones, siempre desde el punto de vista de su autonomía.

Pasando de la lógica al discurso práctico, tenemos que partir del reconocimiento real de cada una de las personas en su proceso de comunicación, buscando un igual derecho en la forma de pensar y con la participación mediante el diálogo en la discusión, respetando su autonomía, tomando en cuenta que cualquier acción que se realice debe ser aceptada por quienes los puede afectar. La importancia del consentimiento se ve reflejada en un dialogo racional en el que con la toma de decisiones pueda justificarse la aportación en la discusión (Cortina, 2005).

La estructura de la sociedad nos proporciona una fuente útil de explicaciones sobre el conflicto al crear intereses específicos que llegan a determinar cuáles son los que giran en torno de esos grupos sociales y cómo encauzar su conducta en una dirección determinada que nos lleve a unir individuos divididos y encontrar intereses comunes compatibles que no generen discordia. Si tenemos objetivos comunes, tendremos intereses comunes.

El derecho está atento a las necesidades sociales. Para Luhmann (2010), la adecuación del derecho no debe tomarse como una traición; debe legitimarse en el marco de los 
valores reconocidos y, dentro de los derechos humanos, es importante recurrir a los valores, en lugar de las normas; y esto tiene un sentido funcional, aunque desde el punto de vista científico, no pueda justificarse ni explicarse de manera suficiente.

En el análisis del comportamiento de la sociedad encontramos que en la observación de estos fenómenos están las respuestas que buscamos en sus diferentes organizaciones, pues es un hecho que las sociedades están ligadas a manifestaciones de poder. Y este es un poder de cohesión que, mediante su aplicación, mantiene las partes unidas con el todo y que, de la mano con sus intereses comunes, constituye el vínculo social, entendiendo la realidad social, en su carácter interrelacional, con los factores que en ella se encuentran: sujetos, instituciones, hechos y diferentes tipos de situaciones y relaciones.

Hay que generar un nuevo paradigma del reconocimiento recíproco de quienes se saben y se sienten como interlocutores válidos; como seres dignos de reconocer el respeto como un elemento de importancia que consiste, entonces, en compartir unos mínimos de justicia que pueden ir ampliándose progresivamente, y en respetar activamente los máximos de felicidad a los que cada persona tiene derecho y según los cuales las exigencias de justicia deben de ser compartidas por todos (Cortina, 2010).

La coincidencia de justicia, validez y eficacia en una norma jurídica es, en gran parte, la medida de su legitimidad. Se encuentra la justicia como un valor ideal para la validez como valor formal y la eficacia como su cumplimiento práctico; así, al ser percibida por la sociedad como legítima, es masivamente obedecida, y el cumplimiento de una norma jurídica — de manera habitual, sin necesidad del recurso de la violenciasuele ser prueba de que es percibida como legítima, pues su aceptación es sinónimo de que la sociedad ve la norma como propia, como suya, como un elemento que le da seguridad y confianza.

En la actualidad, uno de los principales problemas que encontramos es la idea arraigada - no solo en el sistema penal, sino en el social y cultural- de que poco importa o debe importar la persona en el caso de los delincuentes. Se resiste así a la influencia de la cultura de derechos humanos de aplicación general, pues la autoridad penal ha favorecido el establecimiento del imperio del autoritarismo, en 
un medio que, por su delicada naturaleza, debe estar sujeto a la legalidad y al respeto de la condición humana. Por lo tanto, solo en la medida en que el Estado fomente y respete la legalidad y la dignidad de la persona, estará en condiciones de influir positivamente tanto en el delincuente como en la sociedad.

Otro de los problemas principales que tiene la justicia tradicional es la excesiva burocracia y el poco compromiso de quienes son los operadores jurídicos en materia de procuración y administración de justicia. No encontramos un cambio de actitud ante las nuevas circunstancias del rompimiento paradigmático del derecho. Según Aguiló (2015), "el discurso ideológico peca por exceso y el discurso burocrático formalista peca por defecto". Todavía algunos piensan que los problemas en materia de justicia se resuelven por decreto, pues si queremos que funcionen las nuevas reformas, debe haber un cambio de actitud y de cultura jurídica.

La educación es de suma importancia y es la principal forma de combatir los problemas que, como sociedad, enfrentamos. No basta con castigar al culpable para satisfacer la idea de cumplimiento si quien recibe la acción —en este caso, la víctima - queda en una situación de mayor vulnerabilidad. Es necesario promulgar políticas públicas con las que se busque resolver de fondo este tipo de problemas, con base en un proceso educativo cuyo eje rector sea el ser humano y que se identifique con el rol que desempeńa en el grupo social.

Josep Raz (2013) dice:

El respeto por el derecho es un aspecto de la identificación con la sociedad, pues una persona que se identifica a sí mismo con su sociedad, sintiendo que es suya y que le pertenece a ella, es leal a su sociedad. Su lealtad puede manifestarse, entre otras formas, en respeto por el derecho de la comunidad. La actitud de respeto es una manifestación de lealtad pues origina una obligación de obedecer, un reconocimiento de la autoridad. (Raz, 2013)

Las universidades desempeñan un papel preponderante en la difusión del conocimiento, y en materia de justicia restaurativa es importante formular planes y programas de estudio en que, de nueva forma, se vincule la actividad práctica a los valores, en los cuales, como lo establece Luhmann (2010), el eje rector sea el ser 
humano. Se busca que su comportamiento sea el más adecuado, de acuerdo con la satisfacción de sus necesidades, vinculándolo a las decisiones tomadas sobre los conflictos presentados.

Si bien es cierto que la justicia es un valor ideal, la validez un valor formal y la eficacia es su cumplimiento práctico, es de particular importancia resaltar que para que se pueda cumplir con estos tres elementos tendríamos que pensar como formar una sociedad responsable, donde cada persona pueda exigir sus derechos y cumplir con sus obligaciones.

Para Hervada (2011), el buen ciudadano es fruto de sus virtudes; el buen obrar se consigue por hábitos personales. Las normas tienen muchos aspectos técnicos, pero al final van dirigidas a las personas. Las leyes rigen la conducta moral y, en consecuencia, obligan en conciencia; esto se refleja en la formación del buen ciudadano, pues la ley se funda en el orden moral objetivo y se encaminan al bien común social.

Para la Fundación de Cooperación, Investigación y Desarrollo Europa-América Latina (Cideal), existen muchos factores que hacen imposible que, de manera real, los derechos humanos se cumplan. Se trata de elementos que se pueden aplicar a la justicia restaurativa, emprendiendo acciones que contribuyan al reconocimiento de estos derechos, así como es impostergable la propuesta de ciertas acciones que parten de la sencillez en los métodos y herramientas que se han de utilizar, entre otros:

— promover la participación directa de los actores implicados;

— establecer procedimientos de trabajo que resulten sencillos y fáciles;

— basarse en las capacidades de las organizaciones de cooperación;

— poner en el centro de las actividades a los titulares de derecho;

— involucrar y trabajar de manera conjunta con los titulares de deberes;

— aceptar que el desarrollo es un proceso que contribuye a la aplicación práctica de los derechos; 
- buscar componentes que incidan tanto en titulares de derecho como en los deberes, tratando de asegurar que la garantía de uno depende del logro de otros (Gómez-Galán et al., 2015).

Para Bauman (2017), hay que tratar de proteger la dignidad con la que nace el ser humano. La perfección no puede imponerse por ley ni puede imponerse al mundo que asuma una conducta virtuosa. Tampoco se puede forzar al mundo para que sea amable, considerando los seres humanos que lo habitamos, pero hay que intentarlo: vale la pena correr el riesgo para no perder el valor más preciado del ser humano, que es la dignidad.

La justicia restaurativa cumple un factor fundamental en la convivencia armónica del ser humano, en lo cual la dignidad parte de la persona y se reconoce con el respeto reciproco. Ello implica que debemos aceptarnos a nosotros mismos tal como somos y propiciar así una buena convivencia con aquellos con quienes interactuamos, además de construir y de compartir para crecer de manera conjunta con las demás personas y, así mismo, a través de la apertura y del compromiso con la sociedad, en la cual, al final, las decisiones que se tomen en conjunto sean las que más beneficien.

\section{REFERENCIAS}

Aguiló Regla, J. (2015). El arte de la mediación. Madrid: Trotta.

Aristóteles ( 2017). La política. Madrid: Alianza editorial.

Colombia. Ley Nacional de Mecanismos Alternativos de Solución de Controversias en Materia Penal. Diciembre 29 de 2014.

Bauman, Z. (2017). Amor líquido. México: Fondo de Cultura Económica.

Comision Interamericana de Derechos Humanos (2013). Informe sobre el uso de la prisión preventiva en las Américas.

Comisión Interamericana de Derechos Humanos (2017). Capítulo II. Peticiones, casos y medidas cautelares. En Informe anual 2017. (pp. 51-529). Washington: CIDH. Recuperado de http://www.oas.org/es/cidh/docs/anual/2017/docs/IA2017cap.2-es.pdf 
Cortina, A. (2005). Alianza y contrato. Madrid: Trotta.

Cortina, A. (2010). Justicia cordial. Madrid: Trotta.

Frank, J. (1991). Derecho e incertidumbre. México: Fontamara .

Global Peace Index (2019). Global peacefulness improves for the first time in five years, but the world continues to be less peaceful than a decade ago. Recuperado de http://visionofhumanity.org/indexes/global-peace-index

Gómez-Galán, Manuel, Héctor Sainz Ollero, Miguel Albarran Calvo y Ma.Isable Nieblas. (2015). Derechos humanos y empresas: avances desde España. Madrid: Fundación Cideal.

Guarín, E. A. y Aldana, J. (2016). Estado jurisdiccional y bien común. Revista Verba Iuris, 11(36), 13-26.

Hernández Gil, A. (1981). La ciencia jurídica tradicional y su transformación. Madrid: Civitas.

Hervada, J. (2011). Que es el derecho. Pamplona: Eunsa.

Huertas, O. (2019). Politica criminal sistémica: origen rizomático y contribuciones para su reflexión. Ediciones Jurídicas Gustavo Ibáñez Bogotá.

Hulsman, L. (1984). Sistema penal y seguridad ciudadana hacia una alternativa. Madrid: Ariel.

Instituto Nacional de Estadística y Geografía [INEGI]. (25 de septiembre del 2018). Encuesta Nacional de Victimización y Percepción sobre Seguridad Pública (ENVIPE) 2018. https:// www.inegi.org.mx/programas/envipe/2018

Instituto para la Economía y la Paz en México (IEP) (2018). La paz en México se deteriora y el costo de la violencia equivale al $21 \%$ del PIB en 2017. Recuperado de http://visionofhumanity.org/app/uploads/2018/04/MPI-2018-Press-Release_Mexico.pdf

Luhmann, N. (2010). Los derechos fundamentales como institución. México: Universidad Iberoamericana.

Molina González, Y. (2016). Derecho penal del enemigo y dignidad humana. Revista Verba Iuris, 11(36), 135-146.

Nils, C. (1992). Los conflictos como pertenencia. En De los delitos y las víctimas. Buenos Aires: Ad-Hoc. 
PNUD Argentina. (2012). Estudio de la mediación prejudicial obligatoria: un aporte para el debate y la efectividad de los medios alternativos de la solución de conflictos en Argentina. Buenos Aires: Programa de las Naciones Unidas para el Desarrollo (PNUD), Fundación Libra, 2012.

Rawls, J. (2003). Teoría de la justicia: México. México: Fondo de Cultura Económica.

Raz, J. C. (2013). Una teoria de la justicia para la democracia. Buenos Aires: Siglo XXI.

Rousseau, J. J. (2000). El contrato social. México: Austral, .

Turégano, I. (2013). Crisis del estado de bienestar y pérdida de confianza política. En Jerónimo Betegón y Juan Rámon de Páramo (eds.). Derecho, confianza y democracia (pp. 66-67). Albacete (España): Bomarzo.

Weber, M. (2002). Economía y sociedad. España: Fondo de cultura económica . 